\title{
AN EFFECT OF BOVINE SEMINAL PLASMA ON THE IMPEDANCE CHANGE FREQUENCY OF EPIDIDYMAL SPERMATOZOA COLLECTED FROM THE LIVING BULL*
}

\author{
J. P. BENNETT $\uparrow$ AND H. M. DOTT \\ A.R.C. Unit of Reproductive Physiology and Biochemistry, Animal Research Station, \\ 307 Huntingdon Road, Cambridge
}

(Received 1st February 1966)

\begin{abstract}
Summary. Epididymal contents were collected from a bull with an epididymal fistula and from normal bulls after slaughter. When this material was diluted with seminal plasma collected by means of an artificial vagina from either the bull with a fistula or from normal bulls, the impedance change frequency due to the motility of the spermatozoa was reduced as was the length of time for which it could be detected. The fluid obtained from the penis of the bull during electric stimulation with a low voltage did not produce the same effect. The latter fluid had no fructose, a low protein content and a different pattern of inorganic ion concentration from the seminal plasma; the agar gel electrophoresis pattern was also different.

Dilution of epididymal contents with normal seminal plasma did not affect the morphology of spermatozoa or their response to differential staining. Furthermore, neither these characteristics nor the impedance change frequency were affected by a mild degree of temperature shock produced by sudden cooling from $20^{\circ} \mathrm{C}$ to $10^{\circ} \mathrm{C}$.
\end{abstract}

\section{INTRODUCTION}

In many respects mammalian spermatozoa in the cauda epididymidis resemble ejaculated spermatozoa. They are motile without further modifications by the male (Lardy, 1953); they are capable of fertilizing an egg without further modification by the male (Walton, 1927; Young \& Simeone, 1930; Barker \& Gandier, 1957; Dott, 1961); a high proportion of them have discarded their protoplasmic droplet (Branton \& Salisbury, 1947; Hancock, 1955) and they react to eosin in the same way as ejaculated spermatozoa (Ortavant, 1953).

* Presented in part at the Annual Conference of the Society for the Study of Fertility, Nottingham, 1963.

† Present address: British Drug Houses Ltd, Godalming, Surrey. 
On the other hand, epididymal spermatozoa differ from ejaculated spermatozoa in certain important respects, namely, they are more resistant to cold shock (Lasley \& Bogart, 1944a, b; Lasley \& Mayer, 1944), they survive longer in vitro (Dott, 1958) and their metabolism is different (Lardy, 1953). These differences might be due to: (i) the rapid passage of spermatozoa through the final portion of the male genital tract during ejaculation, (ii) reduction of sperm density resulting from dilution with accessory secretions, or (iii) the addition or alteration of some specific factor or factors present in these secretions. Any or all three of these causes could be responsible, and Bialy \& Smith (1959) have indicated that passage through the ampulla can increase the susceptibility of spermatozoa to temperature shock. It was decided to find out, using the continuous flow dialysis technique, in what way the impedance change frequency of spermatozoa taken from the epididymis was affected by dilution with seminal plasma or with other fluids.

\section{MATERIALS AND METHODS}

Epididymal contents were obtained from a bull through a unilateral epididymal fistula (Bennett \& Rowson, 1963) using electrical stimulation with a maximum of $9 \mathrm{~V}$ at 30 cycles/sec across a bipolar rectal probe. The rectal probe was that normally used for electro-ejaculation of the ram and was smaller than the usual bull probe; it consisted of four pairs of brass plates $(150 \times 3 \mathrm{~mm})$ embedded in a perspex core (diameter $25 \mathrm{~mm}$ ). Since the vas deferens on the side opposite to the fistula was sectioned, only a sperm-free fluid could be obtained from the penis during electrical stimulation; this fluid will be designated ESP. Seminal plasma was collected with an artificial vagina when the bull was allowed to mount a teaser cow; seminal plasma obtained by this means will be designated as AvsP. Normal bull semen was obtained with an artificial vagina from bulls whose semen had been used for artificial insemination.

The epididymal material as obtained from the fistula was diluted either with seminal plasma which had been centrifuged at $300 \mathrm{~g}$ for $10 \mathrm{~min}$ to remove cellular debris, or with a solution which will be called the standard diluent containing the following volumes of $0.154 \mathrm{~m}$ solutions: $100 \mathrm{NaCl}, 4 \mathrm{KCl}$, $1 \mathrm{KH}_{2} \mathrm{PO}_{4}, 1 \mathrm{MgSO}_{4} \cdot 7 \mathrm{H}_{2} \mathrm{O}$ and $21 \mathrm{NaHCO}_{3}$; and $400 \mathrm{mg} / 100 \mathrm{ml}$ of fructose. The same solution was also used in the continuous flow dialysis apparatus, the gas phase being $95 \% \mathrm{O}_{2}+5 \% \mathrm{CO}_{2}$.

The impedance change frequency (ICF) was measured in the continuous flow dialysis apparatus (Dott \& Walton, 1960). Samples of spermatozoa were taken before and after dialysis for staining with nigrosin-eosin (Bishop, Campbell, Hancock \& Walton, 1954).

The epididymal plasma was obtained by centrifuging epididymal contents for a period of $20 \mathrm{~min}$ during which the speed was increased slowly to a maximum of $12,000 \mathrm{~g}$ in an attempt to limit the damage to the spermatozoa. The seminal plasma was obtained by similar centrifugation from whole ejaculated semen. Values of the total nitrogen content of epididymal plasma and seminal plasma were obtained using the micro-Kjeldahl method. The proteins in epididymal plasma and seminal plasma were fractionated by agar gel electro- 
phoresis (Bennett \& Boursnell, 1962; Bennett, 1962, 1965). Concentrations of inorganic ions were determined by flame spectrophotometry (Dott \& White, 1964).

Analyses of variance were carried out on results obtained from the continuous flow dialysis apparatus (Dott \& White, 1964).

\section{RESULTS}

Dilution of epididymal material with the seminal plasma obtained with an artificial vagina (AvsP)

Epididymal material obtained from the fistula was divided into three aliquots. One was diluted with 3 vol. of the standard diluent, the second was diluted with 3 vol. of seminal plasma obtained with an artificial vagina (AvsP) from the fistulated bull, and the third aliquot remained undiluted. The Avsp had a nitrogen content typical of normal bull seminal plasma and the fructose, $\mathrm{Na}$ and

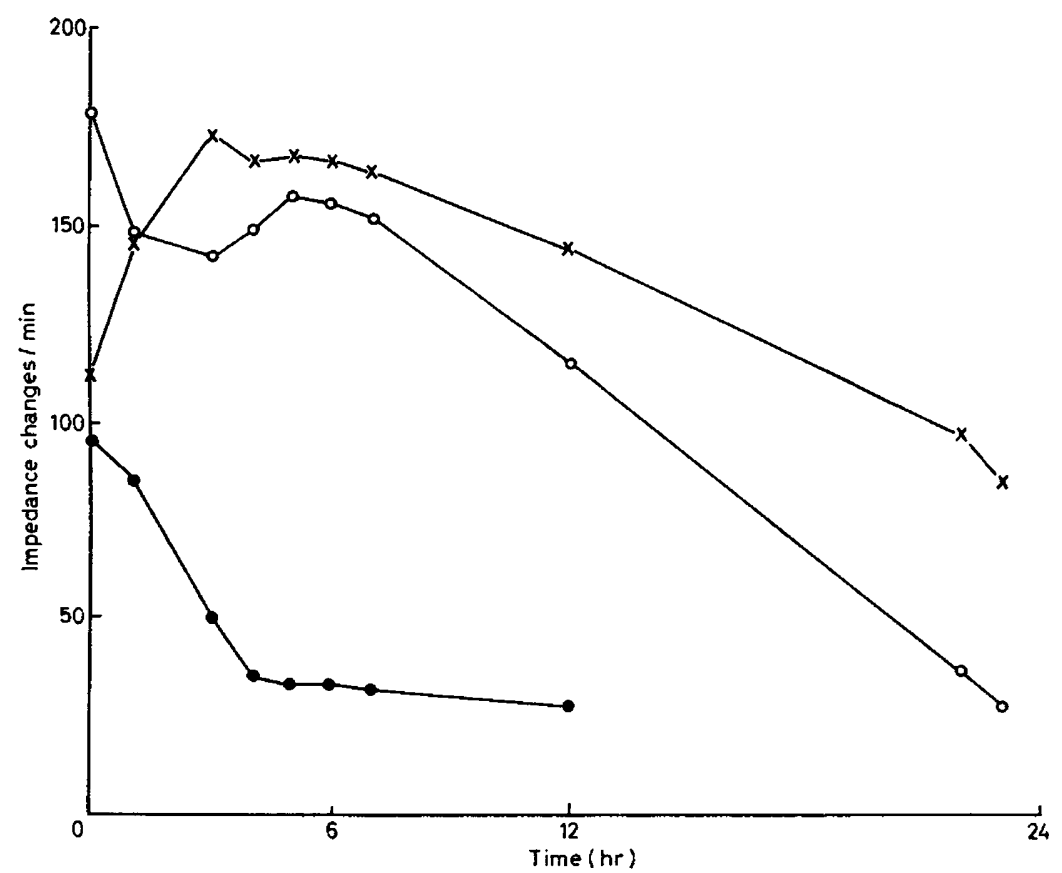

TEXT-rig. 1. The effect of standard diluent and of seminal plasma collected in an artificial vagina (AVSP) on the ICF of spermatozoa obtained from the epididymal fistula of a bull. Epididymal material: $x$, undiluted; $O$, diluted with 3 vol. of standard diluent; , diluted with 3 vol. of AvsP. The curves are the means of four replicate experiments (S.E. $=12 \cdot 54)$.

$\mathrm{K}$ contents were normal (Table 1). The response of epididymal material to dilution with the AVsP was the same in each of four separate experiments (Textfig. 1), namely, there was an immediate fall in the ICF to a value which was lower than that observed in the undiluted aliquot by the time the frrst reading was taken (about 10 min after dilution). The IGF was not detectable in the aliquot diluted with the Avsp 1 day after the experiment was started. In two out 
of the four experiments no ICF was detected in aliquots diluted with AVsP after about 4-hr dialysis. On the other hand, the immediate effect of dilution with standard diluent was to increase the ICF. However, after $1 \mathrm{hr}$ the ICF of the undiluted aliquot increased and that of the aliquot diluted with standard diluent decreased to about the same value. Subsequently there was no significant difference between these two for the $24 \mathrm{hr}$ during which readings were taken.

Dilution of epididymal material with the fluid obtained from the penis by electrical stimulation (ESP)

The fluid (ESP) collected from the penis during electro-ejaculation was shown to have a very low protein content and contain no fructose (Table 1). Unlike urine, seminal plasma and AvsP, it gave a negative biuret reaction. Agar gel electrophoresis spectrographs (Text-fig. 2) showed that it had a different protein pattern from seminal plasma or epididymal plasma. The concentration of $\mathrm{Ca}, \mathrm{Mg}$ and $\mathrm{K}$ in the fluid was lower than in seminal plasma from normal bulls. Its $\mathrm{pH}$ was found to be about $\mathrm{pH} 8 \cdot 2$ with slight variation from sample to sample.

\section{TABLE 1}

THE CONSTITUENTS OF SEMINAL PLASMA FROM THE BULL WITH AN EPIDIDYMAL FISTULA AND FROM NORMAL BULLS (CONGENTRATIONS EXPRESSED IN $\mathrm{mg} / 100 \mathrm{ml}$-MEANS OF THREE ESTIMATES)

\begin{tabular}{l|c|c|c|c|c|c|c|c}
\hline \multicolumn{1}{c|}{ Animal } & Sample & Fructose & $\begin{array}{c}\text { Total } \\
\text { protein }\end{array}$ & $C a$ & $M g$ & $N a$ & $\kappa$ & Ratio Na/K \\
\hline $\begin{array}{l}\text { Control } \\
\text { normal } \\
\text { bulls }\end{array}$ & $\begin{array}{l}\text { Seminal plasma collec- } \\
\text { ted by artificial vagina }\end{array}$ & $320 \cdot 0 \dagger$ & $6480^{*}$ & $34 \cdot 0$ & $12 \cdot 0$ & $208 \cdot 8$ & $175 \cdot 5$ & $1 \cdot 2$ \\
\hline $\begin{array}{l}\text { Bull with } \\
\text { unilateral } \\
\text { epididymal } \\
\text { fistula }\end{array}$ & $\begin{array}{l}\text { Seminal plasma } \\
\text { collected by artificial } \\
\text { vagina } \\
\text { Fluid collected from } \\
\text { penis during electro- } \\
\text { ejaculation } \\
\text { Epididymal plasma }\end{array}$ & $860 \cdot 0 \dagger$ & 5590 & - & - & $272 \cdot 6$ & $173 \cdot 6$ & $1 \cdot 6$ \\
\hline
\end{tabular}

* Mean of four estimations.

+ Single estimations.

$\ddagger$ Calculated from total nitrogen values, assuming $16 \% \mathrm{~N}$ content of proteins.

The design of the experiment in the continuous flow dialysis apparatus using ESP as the diluent was the same as that in which AVSP was used. It can be seen from Text-fig. 3 that dilution with ESP stimulated the ICF in the same way as dilution with the standard diluent but this effect was not maintained. During the first $7 \mathrm{hr}$ of the experiment the aliquot originally diluted with ESP had a lower ICF than those diluted with standard diluent or not diluted at all. Apart from this transient decrease in IGF, ESP had no effect on the ICF or on the length of time for which it could be observed.

These experiments showed that dilution with standard diluent did not alter the ICF of epididymal material in the dialysis apparatus over $24 \mathrm{hr}$ apart 


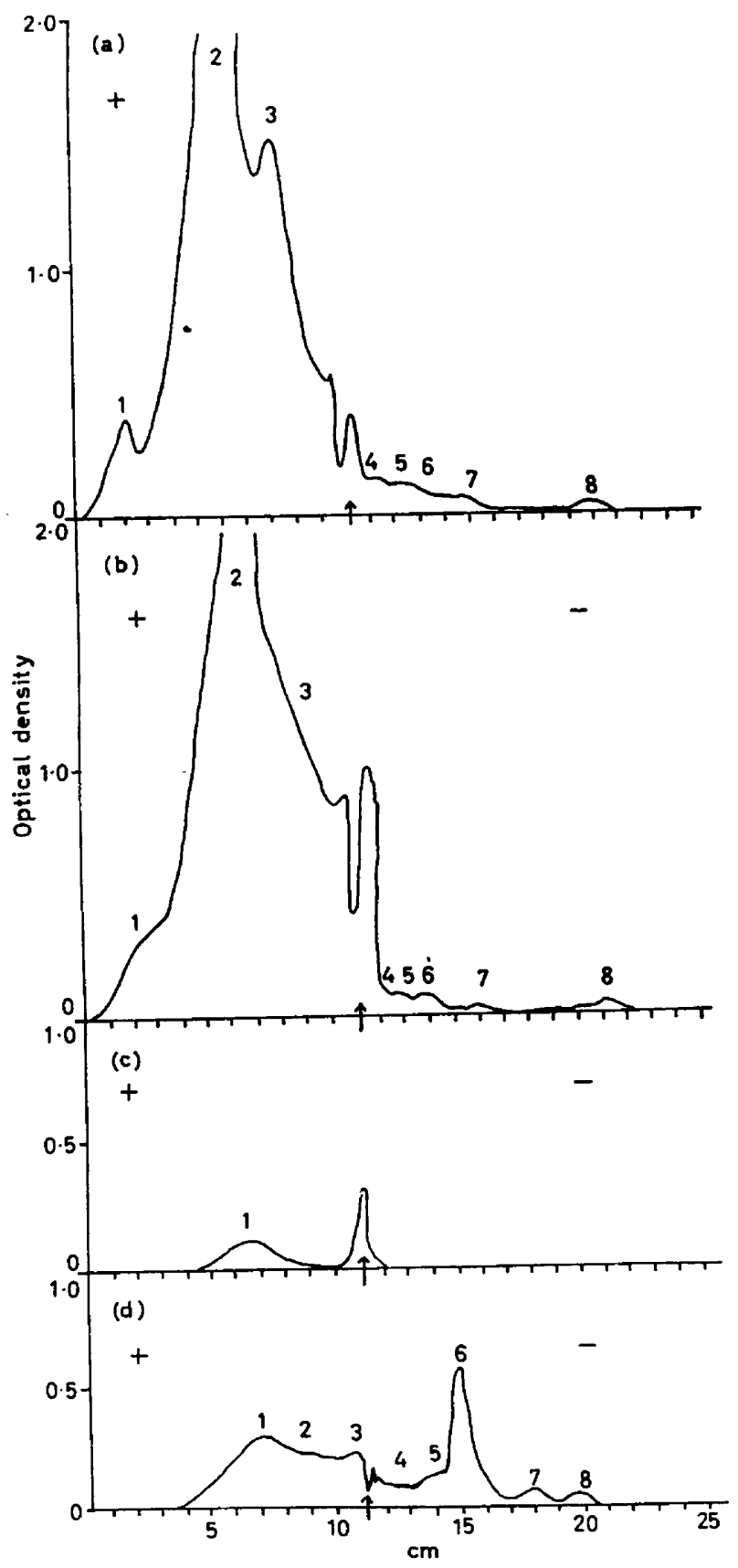

TExT-FIG. 2. Spectrographs of agar gel electrophoresis of protein in: (a) seminal plasma obtained by means of artificial vagina from a normal bull; (b) seminal plasma similarly obtained from the bull with fistula; (c) the fluid obtained from the penis by electro-stimulation of the bull with a fistula; (d) the epididymal plasma from the fistula.

Agar gel: $1.0 \mathrm{~mm}$ thick, $1.0 \%$ (w/v). Buffer: Barbital pH 8.4, $I=0 \cdot 1$. Potential gradient: $16.8 \mathrm{~V} / \mathrm{cm} / 45 \mathrm{~min}$. Nos. 1 to $8=$ protein components. The arrow indicates the position of the original trough for deposition of sample at start of electrophoresis. Electrophoresis was done on a $3 \times 1$ in. microscope slide. The proteins were stained on the slide with naphthalene black $10 \mathrm{~B}$, and the colour intensity on the slide measured in a Unicam spectrophotometer. 


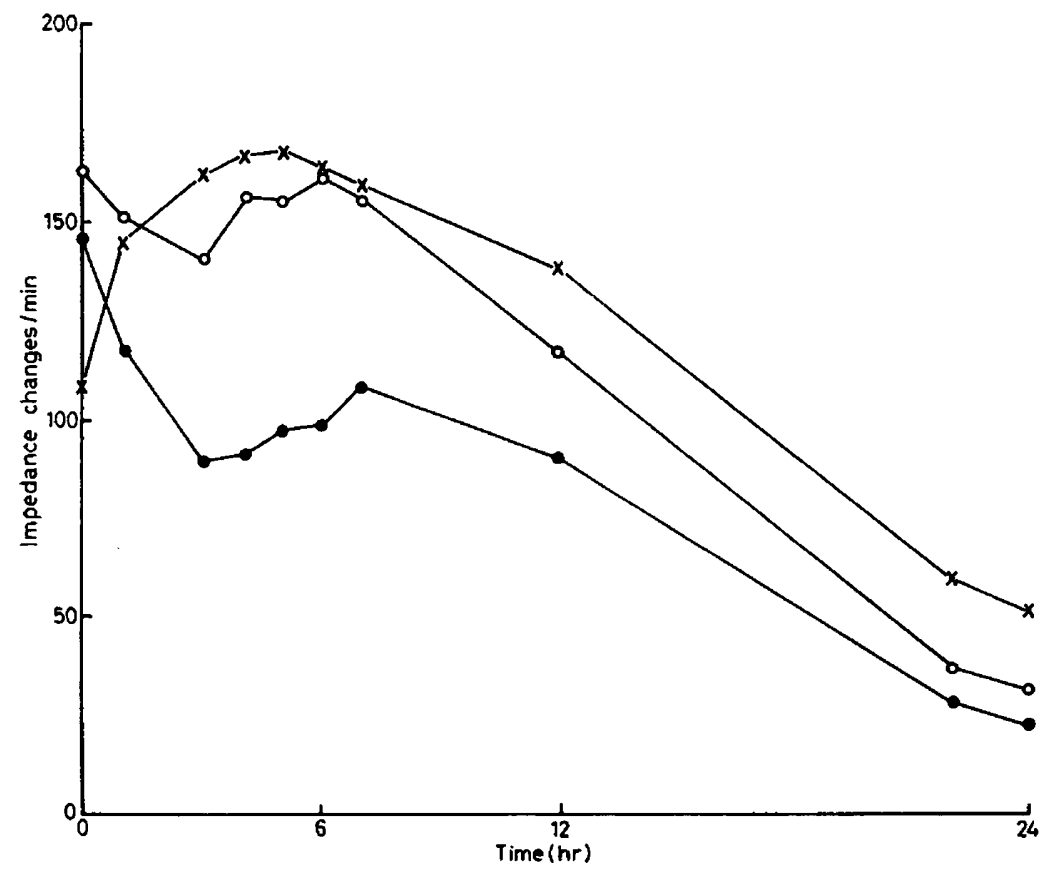

TEXT-FIG. 3. The effect of standard diluent and the fluid obtained from the penis by electro-ejaculation (ESP) on the IGF of spermatozoa from the epididymal fistula of a bull. Epididymal material: $x$, undiluted; 0 , diluted with 3 vol. of standard diluent; 0 , diluted with 3 vol. of ESP. The curves are the means of six replicate experiments (S.E. $=10 \cdot 72$ ).

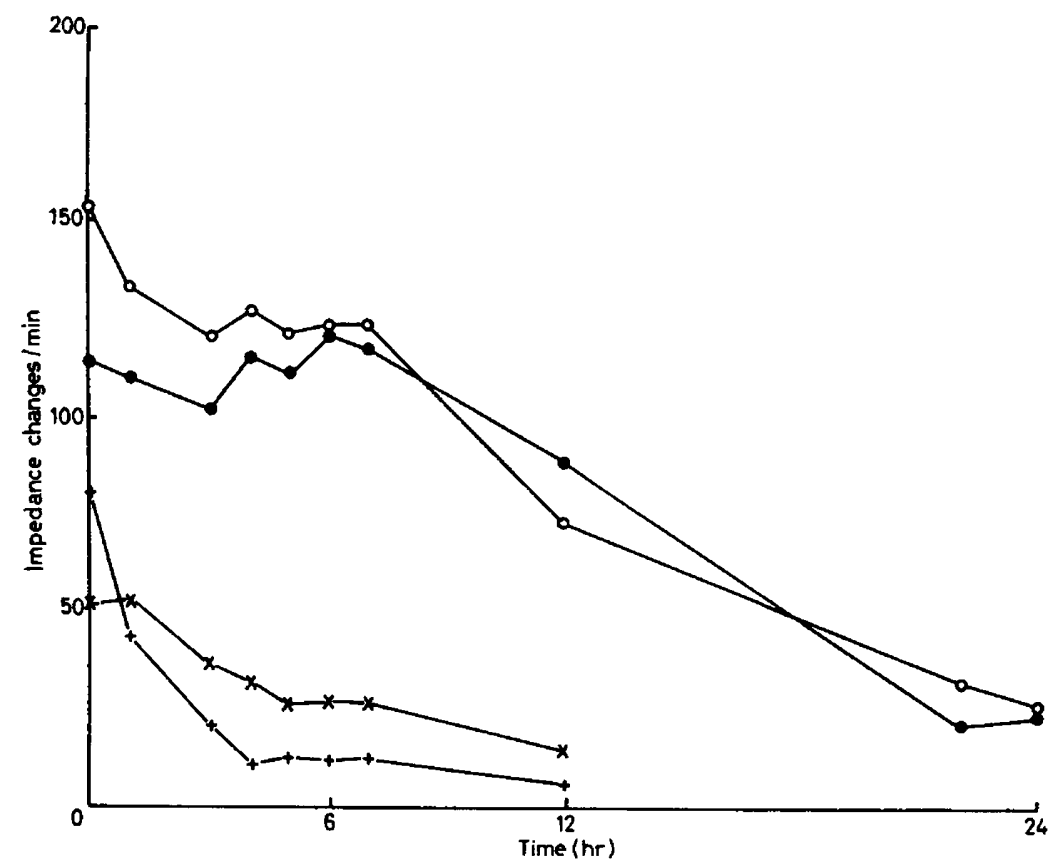

TEXT-FIG. 4. The effect of dilution and cooling on the ICF of spermatozoa from the epididymal fistula of a bull. Epididymal material: $O$, diluted with the standard diluent, but not cooled; $\theta$, diluted with the standard diluent and cooled $10^{\circ} \mathrm{C}$ suddenly; + , diluted in AVSP but not cooled; $x$, diluted in AVsP and cooled $10^{\circ} \mathrm{C}$ suddenly. The curves are

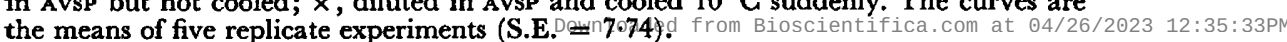


from an initial stimulation. Therefore, the undiluted aliquot of epididymal material was omitted from subsequent experiments so that the semen could be used to fill two dialysis sacs instead of one.

Effect of rapid cooling from $20^{\circ} \mathrm{C}$ to $10^{\circ} \mathrm{C}$ on diluted epididymal material

The epididymal material was divided into two samples. One sample was diluted with standard diluent and the second with AVsP. The rate of dilution was the same as in the previous experiment. One aliquot of epididymal material diluted with standard diluent and one diluted with seminal plasma, were

TABLE 2

EFFECT OF RAPID COOLING FROM $20^{\circ} \mathrm{C}$ TO $10^{\circ} \mathrm{C}$ OF BULL EPIDIDYMAL SPERMATOZOA ON THE MORPHOLOGY AND DIFFERENTIAL STAINING WITH NIGROSIN EOSIN

\begin{tabular}{|c|c|c|c|c|}
\hline & \multicolumn{2}{|c|}{$\begin{array}{l}\text { Untreated } \\
\text { spermatozoa }\end{array}$} & \multicolumn{2}{|c|}{$\begin{array}{c}\text { Cooled } \\
\text { spermatozoa }\end{array}$} \\
\hline & $\begin{array}{l}\text { Standard } \\
\text { diluent }\end{array}$ & $\begin{array}{l}\text { Seminal } \\
\text { plasma }\end{array}$ & $\begin{array}{l}\text { Standard } \\
\text { diluent }\end{array}$ & $\begin{array}{l}\text { Seminal } \\
\text { plasma }\end{array}$ \\
\hline$\%$ Stained spermatozoa & $19 \cdot 0$ & $17 \cdot 4$ & $21 \cdot 8$ & $30 \cdot 4$ \\
\hline $\begin{array}{l}\text { Total \% deformed } \\
\text { spermatozoa }\end{array}$ & $8 \cdot 4$ & $16 \cdot 8$ & $13 \cdot 0$ & $28 \cdot 0$ \\
\hline $\begin{array}{l}\% \text { Spermatozoa with coiled } \\
\text { tails and tail-less heads }\end{array}$ & 6 & $14 \cdot 8$ & $12 \cdot 8$ & $25 \cdot 8$ \\
\hline
\end{tabular}

cooled rapidly to $10^{\circ} \mathrm{C}$ by shaking for $20 \mathrm{~min}$ in glass test tubes immersed in a beaker of water at this temperature. Samples were taken for nigrosin eosin staining before and after cooling. The experiment was repeated on five different samples. Except for the initial ICF, the curves for cooled and uncooled material did not differ from each other significantly (Text-fig. 4). Again, however, dilution with Avsp brought about a reduction in the ICF and in the length of time during which it could be detected.

Abnormalities of sperm morphology were counted, particularly those associated with cold shock. One hundred spermatozoa in each of the four treatments in all five replicates of the experiments were counted (Table 2). The number of stained spermatozoa; those with coiled tails, heads without tails, and spermatozoa with other abnormalities were noted. The statistical analysis ( $t$-test) of the results showed that none of the differences between treatments or between replicates was significant.

\section{Experiments with material recovered at autopsy}

One of the advantages of using a bull with an epididymal fistula was that one animal could supply material for a number of experiments. A disadvantage was that on any one occasion the volume was limited as there was only one bull with a patent epididymal fistula. Therefore, in addition to material obtained from the fistula, bull reproductive tracts were obtained on three separate occasions from the local slaughterhouse and, after the contents had been 
recovered from the epididymis (Dott, 1958), each sample was diluted with the seminal plasma (obtained by centrifugation of whole semen) from three different normal bulls. In each case the ICF was reduced as was the length of time it could be detected, the result, therefore, being the same as when epididymal material from the bull with a fistula was diluted with AVSP.

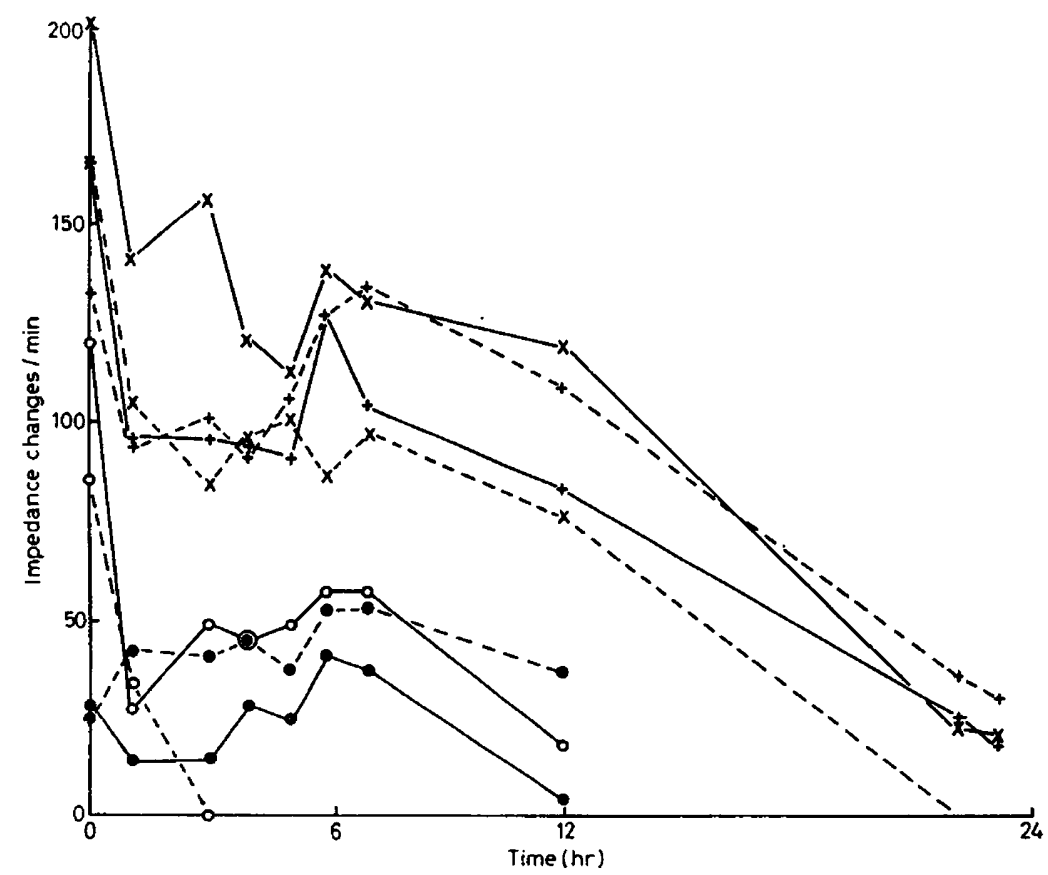

Text-FIG. 5. The effect of dilution and cooling on the ICF recorded in a single experiment in which spermatozoa from the bull with a fistula (continuous line) were compared with those taken from the epididymis of an animal after castration (dotted line). Epididymal material: $\times$, diluted with a standard diluent, not cooled; + , diluted in standard diluent but cooled to $10^{\circ} \mathrm{C}$ suddenly; $O$, diluted in AvSP, not cooled; $O$, diluted in AvsP but cooled $10^{\circ} \mathrm{C}$ suddenly.

Finally, epididymal material from the bull with a fistula and from an epididymis obtained at slaughter was diluted with AvsP from the bull with a fistula. Samples were taken and cooled as described above. The results of this single experiment are depicted in Text-fig. 5. Again dilution with such seminal plasma depressed the ICF. The cooling had no effect on the IGF values.

\section{DISGUSSION}

When the bull with an epididymal fistula was allowed to ejaculate into an artificial vagina, the seminal plasma (AVsP) had a normal fructose content and can therefore be assumed to have included the seminal vesicle secretion (Mann, 1948). In certain other respects, in particular the agar gel electrophoresis pattern, the ejaculated seminal plasma from the bull with a fistula was similar to seminal plasma from control bulls (see also Quinn, White \& Wirrick, 1965). However, when the bull with a fistula was stimulated by applying a low voltage 
across a small bipolar rectal probe, a clear fluid (ESP) was obtained from the penis which was fructose-free and, virtually, free from nitrogen and therefore did not contain vesicular secretion. The ESP had a $\mathrm{Ca}$ and $\mathrm{Mg}$ concentration and $\mathrm{pH}$ similar to the pre-sperm fraction of a complete electric ejaculation as defined by Lutwak-Mann \& Rowson (1953); that fraction did not contain vesicular secretion.

When esp was added to epididymal spermatozoa their impedance change frequency, morphology and affinity for eosin were unaffected. However, the addition of AVSP to epididymal spermatozoa immediately depressed the impedance change frequency though the other characteristics remained unaltered. The precise cause of this effect remains to be explored.

Hancock (1951) reported that a rapid drop in temperature from $30^{\circ} \mathrm{C}$ to $20^{\circ} \mathrm{C}$ was sufficient to produce a decrease in the proportion of ejaculated bull spermatozoa which did not stain with the nigrosin eosin stain, and Bishop \& Hancock (1951, quoted in Hancock, 1952) showed that this could be correlated with a depression in the oxygen uptake and fructolysis of the shocked spermatozoa. On the other hand, White (1960) found only a slight decrease in the proportion of unstained ejaculated bull spermatozoa after sudden cooling to $10^{\circ} \mathrm{C}$; however, he gave some evidence that below $15^{\circ} \mathrm{C}$ some degree of temperature shock may be observed. In our experiments we subjected bull epididymal spermatozoa diluted with seminal plasma to a slight temperature shock by rapid cooling from $20^{\circ} \mathrm{G}$ to $10^{\circ} \mathrm{C}$, but the impedance change frequency, the morphology and the differential staining with nigrosin eosin were all unaffected. There is no evidence to show whether this was because we were using epididymal spermatozoa which had not been through the ampulla (Bialy \& Smith, 1959) or because the temperature shock was not sufficiently severe. A study of the effects of various degrees of temperature shock on bull spermatozoa is now in progress.

\section{REFERENCES}

Barker, C. A. V. \& Gandier, J. C. C. (1957) Pregnancy in a mare resulting from frozen epididymal spermatozoa. Can. 7. comp. Med. 21, 47.

Bennett, J. P. (1962) A continuous scanning attachment for the spectrophotometric measurement of proteins after agar gel electrophoresis. Biochim. biophys. Acta, 63, 398.

Bennett, J. P. (1965) Quantitative comparisons of the proteins of the seminal plasmas of bull, ram, rabbit and boar by agar gel electrophoresis. F. Reprod. Fert. 9, 217.

BenNett, J. P. \& Boursnell, J. C. (1962) Improvements in the method for the electrophoretic separation of proteins on agar gel. Biochim. biophys. Acta, 63, 383.

Bennett, J. P. \& Rowson, L. E. A. (1963) A fistula for the collection of epididymal semen from the bull. F. Reprod. Fert. 6, 61 .

Bialy, G. \& Smith, V. R. (1959) Cold shock of epididymal spermatozoa. F. Dairy Sci. 42, 2002.

Bishop, M. W. H., Campbell, R. C., Hancock, J. L. \& Walton, A. (1954) Semen characteristics and fertility in the bull. F. agric. Sci. 44, 227.

Branton, G. \& Salisbury, G. W. (1947) Morphology of spermatozoa from different levels of the reproductive tract of the bull. F. Anim. Sci. 6, 154.

Dotr, H. M. (1958) Species differences in the metabolism of epididymal spermatozoa. Stud. Fert. 10, 73.

Dотт, H. M. (1961) The fertility of ram semen treated in the continuous flow dialysis apparatus. Proc. IVth int. Congr. Animal Reproduction, The Hague.

Dotт, H. M. \& WALton, A. (1960) Effects of dilution and washing on ram spermatozoa studied by the flow dialysis technique. F. Reprod. Fert. 1, 350. 
Dotт, H. M. \& White, I. G. (1964) Effect of potassium on ram spermatozoa studied by a flow dialysis technique. 7. Reprod. Fert. 7, 127.

Hancock, J. L. (1951) A staining technique for the study of temperature shock in semen. Nature, Lond. 167, 323.

Hancock, J. L. (1952) The morphology of bull spermatozoa. 7. exp. Biol. 29, 445.

Hancock, J. L. (1955) The disintegration of bull spermatozoa. Vet. Rec. 67, 825.

LARDY, H. A. (1953) Factors controlling rates of metabolism in mammalian spermatozoa. Mammalian Germ Cells. Ed. G. E. W. Wolstenholm. Churchill, London.

LAsley, J. F. \& Bogart, R. (1944a) A comparative study of epididymal and ejaculated spermatozoa of the boar. J. Anim. Sci. 3, 360.

LASLEY, J. F. \& BOGART, R. (1944b) Some factors affecting the resistance of ejaculated and epididymal spermatozoa of the boar to different environmental conditions. Am. J. Physiol. 141, 619.

LASLEY, J. F. \& MAYER, D. T. (1944) A variable physiological factor necessary for the survival of bull spermatozoa. F. Anim. Sci. 3, 129.

Lutwak-ManN, C. \& Rowson, L. E. A. (1953) The chemical composition of the presperm fraction of bull ejaculate obtained by electrical stimulation. F. agric. Sci. 43, 131.

Mann, T. (1948) Fructose content and fructolysis in semen. Practical application in the evaluation of semen quality. F. agric. Sci. 38, 323.

Ortavant, R. (1953) Existence d'une phase critique dans la maturation epididymaire des spermatozoides de belier et de taureau. C.r. Séanc. Soc. Biol. Paris, 147, 1552.

Quinn, P. J., White, I. G. \& WirRICK, B. R. (1965) Studies of the distribution of the major cations in semen and male accessory secretions. J. Reprod. Fert. 10, 379.

Walton, A. (1927) The relation between 'density' of sperm suspension and fertility as determined by artificial insemination of rabbits. Proc. $R$. Soc. B, 101, 303.

White, I. G. (1960) The susceptibility of spermatozoa to cold shock. Int. F. Fert. 5, 195.

Young, W. G. \& Simeone, F. A. (1930) Development and fate of spermatozoa in the epididymis and vas deferens in the guinea pig. Proc. Soc. exp. Biol. Med. 27, 838. 